\title{
Educating towards Musical Historical Heritage: What Difficulties?
}

\author{
Elita Maule $^{1}$, Dario De Cicco ${ }^{2}$ \\ ${ }^{1}$ Conservatory of Music of Bolzano-Bozen, Bolzano, Italy \\ ${ }^{2}$ Conservatory of Music “Giuseppe Verdi” of Turin-IT, Turin, Italy \\ Email: elita.maule@alice.it, dariodecicco@alice.it
}

Received August 12 ${ }^{\text {th }}, 2012$; revised September 15 ${ }^{\text {th }}, 2012$; accepted September $27^{\text {th }}, 2012$

\begin{abstract}
How does one set about helping children and teenagers to understand the different musical styles and genres, the historical context pertaining to works of music and composers, or the historical aesthetic appreciation of the musical repertoire? Are these aims achievable and simple to attain with students? This article intends to focus on this very aspect, deemed important and included in all the national curricula throughout Europe. It will show that the teacher's familiarity with the specialist musical code could lead him/her to take for granted technical knowledge that the student does not actually possess and that the problems of temporal conceptualization should represent an object of careful reflection for all teachers.
\end{abstract}

Keywords: Music Education; History of Music; Psychopedagogy

\section{Introduction}

“All European countries have arts and cultural education curricula setting out learning aims/outcomes to be achieved. Depending on whether those curricula are structured as an integrated whole or as a collection of separate subjects, some learning aims/outcomes may be defined more specifically for the visual arts, music, drama, dance, media arts and crafts” (European Commission, 2009).

As far as music is concerned, the aims shared by almost all countries of the European Union concern the development of artistic skills, which generally involves "learning the different artistic styles and genres. In that regard, some countries refer to a repertoire of specific works, in particular for music and drama. Artistic understanding tends to focus on artistic concepts, such as understanding the characteristics of different means of artistic expression or the relationship between the artist, his or her cultural and physical environment and his or her works" (European Commission, 2009).

Critical appreciation (aesthetic judgment) is among the six aims most often referred to, while a third aim common to almost all the countries is an understanding of cultural heritage. "The understanding of cultural heritage is promoted through contact with works of art, as well as through learning the characteristics of works of art produced in different historical periods and of certain artists' works (sometimes from a predetermined repertoire or from artistic 'canons')” (European Commission, 2009).

But how does one set about helping children and teenagers to understand the different musical styles and genres, the historical context pertaining to works of music and composers, or the historical aesthetic appreciation of the musical repertoire? Are these aims achievable and simple to attain with children and teenagers?

This article intends to focus on this very aspect, deemed important and included in all the national curricula throughout Europe, but still little investigated in the field of didactic re- search (Maule, 2007).

\section{Understanding Historical Time}

Time is an indispensable element of history: "time sticks to its thinking like soil to a gardener's spade”, as Braudel wrote (Braudel, 1980). Even if there is no shortage of attempts to free history from its chronological dimension (as in the covering law theory (Antiseri, 1974) or, regarding music, the a-chronic line of thought initiated by Treitler) (Treitler, 1989), or reduce it to a synchronic type of sociological and anthropological reflection, the observation of times and durations remains a fundamental element of historiography.

Recent trends in the approach to history have brought about new challenges in the world of teaching and, among these, the acquisition of sense of historical time has become a central issue in the debate. This brings into play complex operations such as a precise awareness of the temporal specificity that every historical phenomenon possesses (short, medium, long) and its relation with the formal chronological scale (Bordino, 1983; Mattozzi, 1990a). Furthermore, the student "must understand that even chronology is a product of the historian, who has calculated the year on the basis of natural cycles, and that calendars (which may be solar or lunar) were invented by societies, by civilisations. The historian [...] invented the idea of the century only at the end of the 1500s” (Le Goff, 1991).

The difficulties linked to the acquisition of historical time, alongside others, not least of all that of a linguistic nature, explain why it is necessary, when planning an effective educational programme on the appreciation of musical historical heritage, to take into accounts the students' capacity to understand and their psychological age.

This question has been the object of various recent studies, which are able to offer the teacher some useful suggestions. "At school we speak of 'time' and in reality we are referring to a myriad of quite different situations; the concept of 'time' is compounded by problems regarding linguistic, logical and nu- 
merical comprehension, and a multitude of information gaps of varying type" (Calvani, 1988).

These are the words of Calvani, who already in the 1980s accused Piaget of having led pedagogic and didactic thought towards absolutist attitudes to the perception of time, just as if it were a notion that we either possess or not.

The studies carried out by the Swiss psychologist on the development of the notion of time tended to demonstrate how children possessed no primary intuition regarding time or duration: initially time seems to be essentially a quality of events and not a dimension in which the events themselves are set (Piaget, 1979).

Piaget's theories of the developmental stages have had a determinant influence on pedagogical thought. From the 1960s conditioning also regarded the teaching of history, leading many scholars to have serious doubts about its teach ability: in fact, since the concepts of time indispensable for its learning, together with certain necessary formal operations, are not present before the age of eleven-twelve years, it seems somewhat pointless to begin to study it earlier.

While psychology has often tackled the question of temporal comprehension in terms of narration, of physical experiences or "lived time", other issues arise from the comprehension of time linked more specifically to historical contents.

Jahoda, in his investigations about children's notion of time and their progressive interest in history, already proposes five approximate stages of development: at five - six years mythological time (once upon a time) is present; at seven-ten years objective time is present with the possibility to control (some stories about the past are true, others not); at ten - eleven years the continuity between present and past develops along with interest in ancient objects; in pre-adolescence the concept of historical continuity emerges together with interest in historical sequences (first biological, then cultural); finally adolescence sees the development of the concept of historical processuality and the start of historical interpretation (Calvani, 1988).

Historical comprehension and, more especially, historical horizon and the estimation of duration, seem to be closely linked to the more general problem of how the image of history is formed in the mind of the student: in this context we also gain a clearer idea of the reductive effects associated with the transfer and generalization of terms and schemes pertaining to everyday experience. This is what Calvani believes with reference to a study he himself carried out, which confirms the inability of children to estimate duration, with a notable "leveling out" that persists at the age of ten - twelve years.

The image of the unlived past is formed in the minds of children by extending the categories of experience into a mental representation and this can be gathered from the terms they use, taken from everyday language: the meaning of such terms, and their content, is extended to the mental picture of the unknown phenomenon thus explaining the changes that took place in the past. In this way the temporal connotations belonging to the familiar action experienced in the children's daily life are transferred to the realm of history, and historical changes are thus conceptualized as separate events and are focalized as single items similar to those of everyday life (Calvani, 1988).

The author nevertheless concludes by underlining his conviction that temporal acquisitions do not express themselves alone, but are a correlate of various pieces of knowledge and the instruments employed to describe them. The understanding of the durations pertaining to each phenomenon of the past can be considerably improved by supplying crucial information about the nature of the phenomena and by pointing out the fallacy of certain analogies (Calvani, 1988).

Piaget, in fact, seems to have based his thoughts on a too structured view of time and it would probably be more correct to think of a comprehension of time linked to the concrete situations to which they are tied, the specific contents involved in each particular instance.

Moreover, Piaget's studies, or those of his followers, have never attempted to investigate what a child might learn if the learning conditions were modified. And it is precisely this fact that gives rise to the most bitter criticisms, since relying on modifications and changing the existent is a characteristic strategy of teaching: "If we taught history only to people with a refined understanding of adult behaviour and the passage of time, we should probably only teach it as preparation-for-retirement courses [...]" (Watt, 1972).

Data emerging from post-Piagetian studies have thus demonstrated that:

- comprehension difficulties in children are not entirely due to the absence of a notion of time or to logical difficulties, but rather to the linguistic modalities of the account or the extent to which the material presented corresponds to the idea of history possessed by the child (using non verbal requests or clearly structured material, positive answers can already be obtained from children aged four or five years);

- errors in questions of time, at all ages, fundamentally stem from confusion with the spatial dimension since, in common experience, time is more associated with space than with any other variable;

- temporal conducts exist that precede the notion of time and can be consolidated and further developed through teaching (Calvani, 1988). One of the most fundamental examples is the physiological clock that regulates our periodic cycle of life (hunger, sleep, etc.); the temporal horizon, which allows a representation of the past and future starting from the present (our earliest childhood memories become confused with the memories of our parents, influenced in turn by the calendars provided by the society in which we live); the estimation of duration, linked to expectation and the time that opposes the fulfillment of our wishes (Landi, 2005).

From a didactic point of view these considerations have proved highly relevant and justify a course of learning which starts with the construction of our personal history (musical in our case) and then extends to the familiar and thus social in order to consolidate the development of a temporal horizon and the estimation of duration.

\section{From Piaget to Vygotsky}

The line of research linked to the psychology of cognitive development of a Piagetian type, in an attempt to extend the considerations formulated in the scientific and mathematical field also to that of history, demonstrated the incapacity of students to perform hypothetic-deductive reasoning in the latter field before the age of 16.5 years (as opposed to the 12 years reported for science) (Booth, 1994; Hallam, 1967). Hypotheticdeductive thought, like that of time, is also considered an indispensable ingredient in the comprehension of history and of musical history.

The studies carried out in England by Hallam (1967, 1970, 
1972), which would act as a starting point for many others, therefore offer results that are "quite discouraging for teaching: if the obstacles to the development of historical thought are in fact caused by the limits of the intellectual operations available before the stage of formal operations, then, assuming that formal operations are practised some years later in the field of history, one can only adjust one's teaching to the relative stages of cognitive development, or even, more radically, question the very presence of history in school programmes before a certain age" (Rabuiti, 2005).

Subsequent studies, however, have accused Piagetian-type research of adopting inadequate investigation methods; of having used materials and evidence poorly suited to the purpose; of having reduced historical reasoning to a series of formalized techniques and to a "set of logical relations that have more force among psychologists than among historians” (Wineburg, 1996). In any case, as Wineburg observes, "despite the criticisms and negative conclusions, the studies of a Piagetian type [...] not only reopen among psychologists the question of "historical sense" posed by Bell at the start of the century (What is historical sense? And how can it be developed?) and long since abandoned, but also stimulate a series of further studies, with more encouraging results for teaching” (Wineburg, 1996).

The latter include the study promoted by the English government in the 1970s regarding the experimentation of a history curriculum destined for pupils aged between 13 and 16 years, which provided important results in advocating a style of teaching that abandons the chronological and factual approach in favour of one that focuses on the learning of processes and procedures (Wineburg, 1996). Other studies have suggested that difficulties in the learning of history can be ascribed not so much to cognitive factors, but to the context of the teaching, the experience and style of the teacher, and the materials used (Dickinson \& Lee, 1984; Ashby \& Lee, 1987).

The change of perspective that, from the 1980s, influenced research on history education, owes much to an increasing adhesion to the principles of Vygotsky (1935-1983) regarding the development of the mental processes (Wigotskij, 2005). The Russian psychologist considers not only the genetic dimension of the mental processes but also, and above all, the socio-cultural aspects, in which that of language play a determinant role. Of particular interest is what the scholar defines as the "zone of proximal development", "that is to say, the set of cognitive processes that can be stimulated by an opportune educational intervention" (Landi, 2006). The psychologist in fact believes that "the only efficient type of education is one that precedes the development and guides it; it must be directed not so much towards the mature functions, but those in phase of maturation" (Wigotskij, 1980). In other words, by preceding the development in a certain sense, education could enable the consolidation and structuring of roughly sketched processes already in course (Landi, 1987; Wigotskij, 1980).

On this basis, studies on history education therefore turn to the investigation of the problems involved in the understanding of history rather than examining the logical operations involved in the construction of the concepts, that is to say they are concerned with the product as opposed to the process and "focus in particular on-or look for relations between-specific skills in the learning of history, for instance the use of sources, historical reasoning and the understanding of historical concepts, studying the effects of the acquired knowledge (misconceptions and convictions) on specific skills” (Rabuiti, 2005). In this way it is possible to pinpoint, and better delineate, certain issues useful for improving the learning of history instead of sanctioning its unteachability at an early age, as we shall see in the next section.

\section{Linguistic Structure of Historiographic Knowledge}

As pointed out by Ivo Mattozzi (1990b), historiographical knowledge is first and foremost writing, with a compositional, linguistic and rhetorical structure; cognitive operators act on them at a functional level.

Linguistic-conceptual comprehension therefore represents a crucial element in the learning of history, but also a source of difficulty.

Towards the end of the 1980s, especially in the United States, studies of a psycho-linguistic nature began to focus on the students' comprehension of historical textbooks. This resulted in the highlighting of the substantial defects of what are often the only materials available for the study of history: the texts are difficult. The explanations offered are not really explanations because they do not allow us to determine the purpose of an action or an event, to plan for reaching a purpose, or the action produced in response, the result. The texts often presume pre-knowledge that is not present, especially regarding the context of the facts narrated. The conclusions are unanimous: the texts need to be rewritten taking into account models of the comprehension and learning of complex material elaborated by psycho-linguistics (Beck, McKeown, Sinatra, \& Loxterman, 1991).

It has already been shown, for example, how only $13 \%$ $30 \%$ of subjects with an average age of 14 effectively understand the political, economic, religious terms most frequently used in the text-books and how, in reality, the misunderstanding of terms is more common than teachers actually imagine. Even in first-year high school students the results offer little comfort: less than $1 / 4$ of them understand concepts such as Nation, Government or Republic; only towards the age of 16 are they able to distinguish between king and power, while the term "commerce" is differentiated into its various phases still later (Calvani, 1986).

Recent research has nevertheless demonstrated experimenttally that children who were given an adapted history text in which the cause-effect concatenation was explained very clearly, were able to remember much more easily (Rabuiti, 2005; Beck, McKeown, Sinatra, \& Loxterman, 1991).

At the same time, the narration literacy of the text should prevail over the historical literacy, given that the latter is in any case grounded on narration as its basic material and as a means to explain the causal and temporal links; once again it has been experimentally demonstrated how the quality of the texts influences the results of learning.

The history text, then, presents the historical knowledge that has come down to us through specialist research. It has a specific communicative structure that responds to the characteristics of the object in question: narrative when dealing with events, descriptive when dealing with the context in which they are set, argumentative when illustrating the explanation offered by the historian of the issues that he/she has identified. One may, or one must, help the student to understand the fundamental essence of the history text, by exploiting its communicative structure, recognizing its functional structure, so that it 
leads along an autonomous route to the historical knowledge presented in the text. To do this it is necessary to transpose the expert text into one that is functional to the operations of the didactic mediation.

\section{Historical Explanations and Interpretations of the Past in Students}

A second problem investigated by recent research concerns "reasoning in history, explanation and in particular causal reasoning", a source of notable difficulty for the students who tend to adopt categories taken from their everyday experience to explain complex historical phenomena.

Piaget had already noted how children seem to conceive the past in terms of the present, whereas the understanding of how history unfolds tends to upset this perspective; the past is seen as a "reservoir" which contains all the embryons of the machines or tools of today; furthermore, children, like uneducated adults, tend to absolutize their assumptions and believe them universally valid (Calvani, 1988). This aspect can also be said to include the tendency to personalize, that is to say the tendency to explain complex historical phenomena as actions and events that are connected and determined by great personages (individuals or collective entities, these too seen as "persons") overlooking the set of causal variables involved (Carretero, Lopez-Manjon, \& Jacott, 1997; Carretero, Jacott, Limon, Lopez-Manjon, \& Leon, 1994). "The results, though heterogeneous, of the numerous different studies that have been carried out in various counties from the 1970s till today, have nearly always shown how common this phenomenon is, not only among students but also among adults, apart from experts in history. [...] As well as recognizing the quantitative significance of the phenomenon and the difficulties involved in explaining to both children and adolescents, the studies show that such personalization decreases with the increase in age and scholarization [...] and is sensitive both to the type of historical events considered [...] and the type of general cultural education received [...] as well as to the quality of history education at school, so that in Italy and in the 1970s, for instance, the phenomenon is more common in technical and professional schools than in high schools” (Rabuiti, 2005).

In history, as in everyday life, action, whether individual, group, institutional or social, requires an explanation based on the relation between fine beliefs_-values-considered within the context of the action performed and its consequences. This requires, from the students, a historical empathy, in other words the capacity to place themselves in the part of the actor.

Studies carried out in England have shown that such historical empathy in students is characterized by stages each with their particular conception of the past: in the first phase history is stupid and men from the past take on stereotyped roles; at an intermediate level history is considered as a system of explanation but the past is still seen in terms of the present. "Only at a higher level [...] are the differences recognised between the mentality of the past and that of the present and actions are placed in a wider context of beliefs and values" (Rabuiti, 2005).

Recent studies have also focused on the "epistemological beliefs" enacted by the students in order to interpret the past. "Despite the different approaches, the studies highlight the pervasive influence of more or less naive beliefs on the cognitive elaboration of learning processes and the difficulties encountered by the students at various ages. They reveal that the epistemological beliefs change with age, are linked to the level of scholarization and may also come from places far from the school classrooms: from the media, from popular culture, from the church, or from the family. Moreover, they show that it is possible to identify a sequence in the development of epistemological beliefs which [...] go from an absolutist view (where knowledge is absolute and unproblematic) to an absolute relativism (where knowledge is ambiguous and not certain) and finally to a mature epistemology in which knowledge, in continuous construction, is based on the sharing of the norms of investigation" (Rabuiti, 2005).

The picture emerging from the results is therefore quite negative: the conceptions remain reductive even while studying at university.

With this in mind, recent substantiated trends propose a style of teaching based on the comparison of contrasting versions of a historical question, so as to encourage the students to decentralize their personal points of view, or they insist on a greater use of the document in the class, so that students can become accustomed to building history instead of learning its contents by heart.

These are just some of the investigations made by psychologists and scholars of education, and such considerations should also be kept in mind by the teacher in order to profitably teach the appreciation of musical historical heritage set its own cultural context. Moreover, the fact that we have offered information valid for the compulsory school age does not mean that more adult students are exempt from such difficulties. "On this matter it should be remembered that we can never consider the problems linked to temporal assessment to be completely resolved (not even in adults) because the question does not depend solely on maturity, but also on many other factors includeing experience and culture” (Landi, 1988).

The language used by the teacher can often be a frequent cause of comprehension difficulties also in adult students and even more so among students from a lower socio-cultural background, leading, just as frequently, to a lack of interest in the subject. Some studies, in fact, have shown that "the relation between cultural familiarity and the understanding of historical language is clearly confirmed: historical terminology "discriminates" students in relation to their socio-cultural background and the middle school is unable to bridge the gap that already appears wide in the elementary school" (Calvani, 1986).

It seems worthwhile, therefore, to look further into such difficulties and try to identify them more specifically in the realm of music history teaching.

\section{A Problematic History of Music: The Times and Language of Music History}

More than thirty years ago a conference held in Florence about the teaching of music history (Miceli \& Sperenzi, 1987) tackled this sensitive issue: on the one hand it highlighted the problem of the inadequacy of language as a reason for the students' lack of comprehension and demotivation in learning; on the other it criticized the strictly chronological way of handling material which tends to obstruct any real knowledge of the phenomena in question (Maule, 2007).

The history of music, with its peculiar status, seems to present problems of comprehension still greater than those already pointed out for "global" historical comprehension. 
As far as the treatment of time periods is concerned, a brief look through some music education text books for the seconddary school reveals a temporal arrangement of the historical references characterized by the following features:

- the use of temporal parameters such as the 20th century, or the 1800 s, the 1500 s;

- the use of historical-aesthetic terms to describe periods, for example, "Humanism and Renaissance", "Romanticism";

- the use of dates to place events, composers, works;

- the use of "elastic" temporal segmentations linked to a context or civilisation such as "The music of the ancient world", or "The Greeks", “The Romans”.

While approaching the historical aspect in a variety of fashions, text-books, including those aimed at the high school, generally use all the temporal categories outlined above, giving preference to some parameters to speak of certain aspects or historical areas (it is difficult to speak of the ancient world, or of extra-European music, using dates or precise indications of the centuries).

Similar features are also present even in texts that deal with the historical side in the form of "complement files" not arranged chronologically but functional to other didactic projects.

The problem of periodization in music history, which involves and concerns the whole specialist area, seems to be even more accentuated in the education sector, that is, the sector that deals with the diffusion of the historiographic product.

According to Nattiez, for the historian "the difficulty lies in finding convincing criteria for relating the periods to the works, styles and genres on the one hand and the external criteria on the other. In reality no music historian works purely along just one of these three lines at the exclusion of the others" (Nattiez, 2004) and this is why, generally speaking, it becomes necessary to make reference to various different temporal measures. "Music written in a given period can be explained through features characteristic of that same period; the definitions may be those of musical categories (for example musical realism) or notions borrowed from the history of figurative art (baroque, postmodernism) or else from general history (the modern age)" (Nattiez, 2004).

The problem of periodization therefore concerns mainly the point of view adopted by the historian, in other words it hinges on the explanatory grid that justifies the links between the items that have been chosen for investigation; it also depends on the type and quantity of information and traces that have survived till the present. In this way, the music of ancient cultures without written music is investigated by collecting together groups of facts and temporal categories different from those of eras closer to our own which have left us a great deal of music in written form: this explains, for instance, the substantial differences in research methods, in the contents selected, in the periodization, between histories like The rise of music in the ancient world (Sachs, 1943) and The classical style. Haydn, Mozart, Beethoven (Rosen, 1971).

If we now try to put ourselves in the position of the students, we can note how the use of times in the history of music represents a crucial element in its understanding. The simultaneous adoption of various temporal parameters requires the possession of necessary prerequisites that more often than not are lacking:

1) to have learned to attribute meaning to dates and dating;

2) to have assumed sufficient information so as to be able to manage important events within a framework of permanencies and thus to pass from a chronological dimension to one relative to the durations. At times, in fact, despite the chronology, some composers can be placed in a later time-frame, as they do not appear to share the styles of their era. In school text-books, for example, it is now common to find Debussy (1862-1918) and impressionism in the 20th century (Fiorenza, 1992): the student is thus expected to know how to make comparisons and correlations between different measures of time and identify any correspondence between style, century or historical era;

3) to possess an understanding (and to have had sufficient listening experience) of stylistic concepts, techniques, etc. (Romanticism, The age of polyphony, etc.).

Without these prerequisites no real comprehension of the musical phenomena of the past can be achieved. The use of a chronological scale, the conventional measure within which musical contents with their specific temporal connotations of varying type should find a place, remains one of the most complicated obstacles to surmount in order of difficulty. Nobody wishes to deny its importance for arranging events subsequentially. However, the specific scope of historiographical research "is not only to order phenomena in time, but above all to reconstruct a meaningful picture of the past by establishing a variety of relations between the different dimensions of human life [...] in order to make it possible to identify the relations that exist between the different historical periods. Therefore, understanding the meaning of a date does not signify simply setting it at a certain distance from ourselves, it means, above all, being able to identify the logical correlations that make a certain historical phenomenon worthy of being remembered in a certain way with respect to others. Chronology is an essential tool but it must be shaped very gradually. The identification of dates should be seen as the conclusion and not as the beginning of historical knowledge. At school, instead, they begin [...] from the end" (Landi, 2005).

For these reasons, the dates of birth and death of composers, still much loved by the most widespread text-books, or the chronological placement of certain "facts" in time has no basis if we do not first learn to attribute a "sense" to such figures, in other words if we do not know what they are for, or why, or with respect to what. Furthermore, is the detailed use of dates useful and meaningful for a history, such as that of music in the compulsory school that lays no claims to being so specific or detailed?

These considerations confirm the need to provide the school with explicit didactic interventions capable of offering a representation of our historic musical heritage, and its times, which the student can build up little by little. Otherwise, it should come as no surprise if the most able students of music history in universities make frequent anachronistic errors in exams, especially if the questions concern the very ancient times. "The way we perceive certain events to be near or far varies depending on the relevance these have to our culture and in any case is strongly influenced by the state of our knowledge.

The less we know about certain periods the more they tend to contract, also spatially, in the representation we form of them. And the study of history can help us to correct these very defects of short- or long-sightedness, also common among uneducated adults" (Girardet, 1983). We should not even be surprised if the best students in music history remain dumbstricken when faced with simple questions such as: "How long did composers continue to write motets"? Due to the influence of chronology, a temporal category that forms the mainstay of 
much text-book writing, the apparently clever student overlooks the more recently composed motets, linking the form to ancient times because it has been studied exclusively in that context.

The problems of temporal conceptualization and the assignment of times to phenomena of the musical past should therefore represent an object of careful reflection for all teachers. Before starting an activity in the class they should dedicate a few moments to considering the difficulties involved in the task: what conceptual operations are needed for its comprehension? What prerequisites are called for in order to effectively achieve the goals of the operation? Is the selected material adequate and comprehensible? Does the language of the chosen text/texts present any difficulties and could it give rise to any misunderstandings?

The teacher's familiarity with the specialist musical code could lead him/her to take for granted technical knowledge that the student does not actually possess and the effect of interacting factors, derived from everyday experience or from more habitual verbal communication, may often result in error.

Examining an extract taken from a widely used text-book for the Italian middle school, dealing with the life and music of Chopin, Galli offers an example of linguistic difficulty: the terms given here (Table 1) all refer to the style and work of the composer.

The author concludes that "without the careful guidance of the teacher, the reading of the piece in question could lead to misunderstandings or could simply appear meaningless. The language of music history, especially in the extract examined, often uses metaphors, parentheses and quotations; the result is a complex syntactic composition that requires explanation, avoiding, though, the error of oversimplification” (Galli, 1990).

\section{Discussions and Proposals}

The considerations hitherto presented aim to underline how education towards musical historical heritage is a complex operation. Such complexity, long felt and already resolved in the teaching of other areas such as that of "general" history, has never been sufficiently considered within the sector of music, a sector intent on imposing on everyone, irrespective of the level of school and the age of the pupils, a notionalist and verbalist model of learning motivated more by academic music historiography (Universities, Music Conservatories) and the contents

Table 1.

Musical terms.

\begin{tabular}{ccc}
\hline $\begin{array}{c}\text { Common } \\
\text { lexicon }\end{array}$ & $\begin{array}{c}\text { Semantic } \\
\text { polyvalences }\end{array}$ & $\begin{array}{c}\text { Technical expressions and } \\
\text { terms }\end{array}$ \\
\hline Exile & Anonymous folk & Piano \\
Virile & Landscape & $\begin{array}{c}\text { Melodic fantasy } \\
\text { Harmicoriginality and } \\
\text { constructive }\end{array}$ \\
Lyricism & Poeticexpression & \\
Longing/torment & Polonaises & Polonaises \\
Exile & Nocturnes & Nocturnes \\
& & Mazurkas \\
& & Performing modes \\
\hline
\end{tabular}

that is held to be "important", rather than by the sciences of education and developmental psychology.

The fallacy of such transmission of knowledge has led to two consequences: 1) a general disinterest among students in our musical historical heritage; 2) a very poor knowledge of this area at the end of their compulsory schooling (Gasperoni, Marconi, \& Santoro, 2006). Possible solutions to the problem could be:

a) Introducing contents closer to the students' own experience, based, as advocated by the new structuralist approach to history, not on the Great Composers (Beethoven, Bach, Mozart, Rossini...), on their biographies learnt in rote-like fashion and on a list of their works, but on musical contexts experienced by all (What did people at the time of Mozart dance or listen to? Did men and women have the same musical tastes?);

b) Trying to find a link between historical music culture and the experience of young people, perhaps making use of multimedia sources or new technology (What music by Beethoven does Walt Disney use in the cartoon The Music Land and why? What music by Vivaldi is often used as a ring-tone for cell phones?);

c) Trying to exploit local culture, as close and as accessible to the students as possible (What sort of music was played at the mediaeval castle in your town?)

d) Trying to promote a self-study scheme similar to that characterizing historiographical research (not grounded, therefore, on the rote learning of information taken from the pages of a book, but on research, on various texts, the internet, etc. answering questions posed by the students at the outset).

This approach has the advantage not only of motivating the students, but also of taking into account the difficulties involved in studying musical historical heritage, thus guaranteeing the acquisition of methodological as opposed to merely cognitive skills.

\section{REFERENCES}

Antiseri, D. (1974) Contemporary epistemology and history teaching. Rome: Armando.

Ashby, R., \& Lee, P. (1987) Children's concepts of empathy and understanding in history. In The history curriculum for teachers (pp. 62-88). London: Falmer Press.

Beck, I. K., McKeown, M. G., Sinatra, G. M., \& Loxterman, J. A. (1991) Revising social studies texts from a text-processing perspective: Evidence of improved comprehensibility. Reading Research Quarterly, 26, 251-250. doi:10.2307/747763

Booth, M. B. (1994) Cognition in history: A British perspective. Educational Psychologist, 29, 61-71. doi:10.1207/s15326985ep2902_1

Bordino, G. (1983) Notes on the problems of history teaching (pp. 16, 81). Mailand: Quaderni C.I.D.I.

Braudel, F. (1980). Writings on the history (p. 86). Mailand: Mondadori.

Calvani, A. (1986). Teaching history in the primary school (pp. 9-11). Florence: La Nuova Italia.

Calvani, A. (1988) The child, the time, the history (pp. 5, 75-77, 135). Florence: La Nuova Italia.

Carretero, M., Lopez-Manjon, A., \& Jacott, L. (1997). Explaining Historical Events. International Journal of Educational Research, 27, 245-254. doi:10.1016/S0883-0355(97)89732-7

Carretero, M., Jacott, L., Limon, M., Lopez-Manjon, A., \& Leon, J. A. (1994). Historical knowledge: Cognitive and instructional implications. In M. Carretero, \& J. F. Voss (Eds.), Cognitive and instructional processes in history and the social sciences (pp. 357-376). Hillsdale: Lawrence Erlbaum Associates.

Dickinson, A. K., \& Lee, P. J. (1984). Make sense of history. In Learning history (pp. 117-154). London: Heinemann. 
European Commission (2009). Arts and cultural education at school in Europe (pp. 18-20). Brussels: The Education, Audiovisual and Culture Executive Agency.

Fiorenza, G. (1992). Grow with the music. Florence: Le Monnier.

Galli, C. (1990). Contributions toteaching history. La Cartellina, 66, 15-16.

Gasperoni, G., Marconi, L., \& Santoro, M. (2006) Music and teenagers. Practices, tastes, education. Torino: EDT/SIEM.

Girardet, H. (1983). A historical curriculum as construction of conceptual networks. History and knowledge (p. 296). Torino: Loescher.

Hallam, R. N. (1967). Logical thinking in history. Educational Review, 19, 183-202. doi:10.1016/S0883-0355(97)89732-7

Hallam, R. N. (1970). Attempting to improve logical thinking in school history. Research in Education, 21, 1-23.

Hallam, R. N. (1972). Thinking and learning in history. Teaching History, 15, 337-346.

Landi, L. (1987). A history without time? La Vita Scolastica, 5, 6.

Landi, L. (1988). Methods and techniques to teach history in the primary school (p. 85). Teramo: Giunti e Lisciani.

Landi, L. (2005). Telling the prehistory (p. 20). Rome: Carocci-Faber.

Landi, L. (2006). Teaching history to children (p. 9). Rome: Carocci.

Le Goff, J. (1991). Research and schooling of history (pp. 23-24).

Florence: La Nuova Italia.

Mattozzi, I. (1990a). The historical culture: A model of construction.

Faenza: Faenza Editrice.

Mattozzi, I. (1990b). A curriculum for the history. Curricularproposals and educational experiences for the primary school. Bologna: Cappelli.

Maule, E. (2007). History of music: How to teach it in the school. Pisa: ETS.

Miceli, S., \& Sperenzi, M. (1987). Teaching history of music. Proceedings of the international conference. Florence: Olschki.

Nattiez, J. J. (2004). History or histories of music? Enciclopedia della musica, $I V$ (p. XXV). Torino: Einaudi.

Piaget, J. (1979). The development of the time concept in the child (pp. XX-XXI). Florence: La Nuova Italia.

Rabuiti, S. (2005). Clio assessment. In Quaderni di Clio '92 (p. 9). Faenza: Polaris.

Rosen, C. (1971). The classical style Haydn, Mozart, Beethoven. London: Faber \& Faber.

Sachs, C. (1943). The rise of music in the ancient world. New York: Norton.

Treitler, L. (1989). Music and the historical imagination. London: Harvard University Press.

Watt, D. G. (1972). The Learning of History (p. 14). London: Routledge Kegan.

Wigotskij, L. (1980). Thought and language (p. 130). Florence: GiuntiBarbera.

Wineburg, S. S. (1996) The psychology of learning and teaching history. In Handbook of educational psychology (pp. 423-437). New York: Macmillian. 